\title{
Agreste (Malva-Rosa)
}

\section{Newton Moreno}

idéia deste texto é servir como exercício de narrativa para um ator-contador(atriz).

O narrador pode assumir todas as outras personagens, viúva, o padre, o delegado, ou as vozes dos moradores.

Ou dispor de outro(s) ator(es) que cria(m) uma partitura física para determinados momentos da estória. Da união destas duas linguagens - a oralidade e a dança-teatro; verbo e movimento - será feito o espetáculo.

\section{Um(a) narrador(a).}

Velho(a) contador(a) de estórias. Daqueles que reúnem um grupo ao redor da fogueira ou embaixo de uma árvore com uma violalsanfona, pontua suas histórias com as músicas e acordes que saem de seu instrumento. Ele(a) recebe o público, dá o clima de cada passagem do texto, pausas, enfim, é o grande condutor da cena.

\section{CONTADOR(A)}

Ele andava muito para encontrá-la. Mas quando se viam, ficavam, no mínimo, a cinco metros de distância. Nem um centímetro a mais ou a menos. Exatos cinco metros. Sempre. Uma cerca os separava.

Ela sorria de um lado, ele, do outro.
Ele deixava uma flor na cerca, ela ia buscar. Ela deixava seu perfume na cerca, ele ia buscar.

Eram tímidos como caramujo. Precaviam-se. Se chegassem muito perto, Deus sabe o que aconteceria. Tinha alguma coisa no amor deles que não devia acontecer. Mas aconteceu.

Por meses, anos. Eles e a cerca.

Ele deixava um beijo na madeira do cercado, ela colhia.

Foram se estreitando. Chocando sua intimidade. Confiavam um no outro, que nem a terra na chuva.

Ele deixava sangue no arame da cerca, ela ia enxugá-lo.

Às vezes, podia demorar um mês para se encontrar. Ela deixava um pedaço de chita do vestido, ele amarrava na enxada. Era lavrador no Nordeste do país. Reino de areia e de sede. Era honesto. Forte. De pele marcada. Não dá para saber a idade. Eram como rochas velhas secando na espera. Sua cultura era o sol. Sua família era o sol.

Ele deixava cuia. Ela colocava cuscuz. Ele comia, sorrindo. Ele devolvia a cuia e ela ia buscar e... descobriram um furo na cerca!!!

Música. Os atores que representam o casal estudam o buraco, cada um do seu lado. Tempo.

Newton Moreno é dramaturgo e pesquisador, mestre em artes cênicas pelo ECA-USP. 


\section{CONTADOR(A)}

Incertos. Fingiram não vê-lo. Era um buraco enorme como o sertão. Fingiram por uma semana. Duas. Um mês. A dúvida.

Mas o buraco crescia, como querendo se exibir. Amostrado. A cada vez que voltavam, estava maior.

E eles de butuca no furo. Parecia um açude, tentando-os com sua água escura, escura, cor de enigma.

Se ele tocasse nela? Se ela aceitasse ele?

Às vez, é preciso muita coragem para dar um passo.

Tempo. Ação dos atores estudando o buraco.

\section{CONTADOR(A)}

Naquela manhã, ela foi sozinha. Firmou-se frente ao buraco. Tomou coragem e cruzou. Acalmou-se aos poucos. Respirou, deu um passo, dois. Parecia um astronauta movimentando-se pela primeira vez na Lua. $\mathrm{O}$ ar é o mesmo. $\mathrm{O}$ Sol é o mesmo. O coração era outro. Uma criança brincando onde não devia. Trelosa. O que ela não sabia, era que ele estava lá. Olhando-a boquiaberto detrás do arbusto. Ela dançava, grunhia, sujava-se de terra.

Ele sorria.

Quando se perceberam, paralisaram. Mas muito, muito tempo. Ele ultrapassou o limite dos 5 metros, aos poucos. Alcançou o hálito nervoso dela. Talvez 45 centímetros. Atravessaram!

Música. Poeira subindo.

\section{CONTADOR(A)}

Correram. De tanta euforia e medo. Levantando uma nuvem de poeira por onde passavam. Uma nuvem como há muito o Nordeste não via.

Fugiram para longe.

Pensaram: chegariam no mar de tanto passo.

Chegariam, se tivessem corrido esse tanto de chão pro outro lado.

Avexaram-se no passo com medo de mudar de idéia. $\mathrm{O}$ medo deu pressa. As lágrimas dela tentavam marcar no chão um caminho de volta. Num determinado ponto, deram-se as mãos e tranquilizaram-se.

Perfuraram o Brasil mais fundo. Desmontaram dos pés no meio da seca. E pensaram que não devia existir um lugar mais árido que aquele. Mas o Nordeste surpreende a gente. Vai ter sempre uma rês mais murcha e um filho mais moribundo. $\mathrm{O}$ peito arfava de contentamento e pavor. Era como se inspirassem alegria e expirassem receio. Uma pausa de um silêncio pesado.

Desviavam olhares, cabisbaixos. Não queriam mostrar a dúvida passeando dentro dos seus olhos. Pior: não queriam ver nos olhos do outro a dúvida.

Voltar? Mesmo se quisessem, não saberiam como. As pegadas úmidas já nem existiam; foram sorvidas com força por aquela terra saudosa da água.

Deitaram os corpos na sombra de um mandacaru. Na margem do que fora um riacho. O sol já lhes roubara o senso, o tino.

Algo morno crescia na alma. Era um vapor no forno, no berço, na fôrma do novo afeto. Estavam à beira de um desmaio. A razão já se afogava com o sol a pino quando uma mulher se desenhava ao longe feito miragem. Veio lenta, feito a justiça. Aproximou-se.

Falava com eles, mas eles não ouviam uma só palavra. Em lugar das palavras, só conseguiam escutar os sons das águas. Da sua boca tudo soava gotas de chuva, barreiros cheios, açude vazando, água da calha. Os sons dela eram todos molhados. Ela falava como um rio, aquosa. Foi essa mulher quem os salvou.

Levou ao povoado e tratou de acomodálos.

Apearam neste arraial. Um pouco de jabá, sombra e água barrenta e recobraram o prumo. Lá, eles plantaram a vida.

Música pára. O texto segue com a poeira ainda alta.

Construíram um casebre.

Cercaram com arame, mas para se prender por dentro.

Não queriam conhecer os outros, antes de saberem de si. 
Até então, nada das coisas que se permitem marido e mulher. A carne é um compromisso mais definitivo. Passou esta cerca, o gado é marcado.

E a noite chegou mais clara que o dia. E os olhos não se prendiam num abraço de jeito maneira. Mas os dois foram se descobrindo aos poucos.

Ela começou pelo seu rosto. Os cabelos dele. Escuros, cabeleira cabocla de filho de índio brabo. Farto e espesso. Devia de pesar na mão. Devia de quebrar pente fraco.

Ele fazia o percurso inverso. Pôs os olho nos cambito da moça. Umas canela fina, mas bronzeada, que lhe agradaram os sentido.

E assim se seguiu a malevolente investigação: ela descendo os olhos, ele subindo a vista.

Ela admirava era a dentição dele. Perfeitinha. Os dentes que faltavam em cima, ele tinha embaixo; e vice-versa. De modo que quando ele sorria, os dentes se encaixavam num sorriso de um fileira só, mas sem buraco. Mas sorria bonito ele!

Uma semana depois, eles se tocaram. Antes disso, só as mãos no meio da correria.

Ouvia-se uma pele rachando na outra, acostumando-se um ao outro, deixando o tempo passar. Um dia, ela se escondeu embaixo do lençol; ele apagou o candeeiro. Por anos, este foi o sinal, o código. Sumir-se embaixo do lençol. Cobrir a luz com o escuro. E ele apagou muito aquele pavio.

Como marido e mulher, viveram por vinte e dois anos.

Até hoje.

Música cessa. Poeira baixa. Homem deitado, mulher a seu lado.

Velhinhas entoam incelenças.

\section{CONTADOR(A)}

Morto, ainda vestido para o trabalho, ele dormia sob a mesa da sala. Uns candeeiros velavam o corpo, resguardando sua imagem.

As vizinhas foram adentrando. Vinham fazer quarto pro morto. Já cantavam em suas casas e traziam seus cantos no suspiro da noite.
Todas empregavam as melhores palavras de um parco vocabulário para defini-lo.

\section{VOZES}

"Da mais alta estima", "Pareia de Anjo", "Elegante como Jesus", "Íntegro como uma rocha”.

\section{CONTADOR(A)}

Era o mais elaborado do seu idioma. O resto era oração e cântico.

Uma vizinha sentenciou triste:

\section{VE1}

Ele desapareceu a ela.

\section{CONTADOR(A)}

Eram um casal benquisto. Discreto. Pouco festivos. Trabalhadores. Sem filhos. Nem seus nomes eram conhecidos. Seu Zé, Dona Maria, chamavam eles. (Pausa)

Quieta. A noite parecia uma pergunta difícil. Armava um bote/arataca.

\section{(Pausa)}

A sala povoou de mosquito e de mulher. Nunca tão farta. Nem de um, nem de outro. Os homens explodiam seus sentimentos em rojōes. Segredavam às estrelas saudades e estima. Desenhavam lágrimas de luz no céu.

O padre estava a caminho para a extrema-unção. Amuada e com fome, a viúva remendava o terno puído para o enterro. O que deveria vesti-lo no casamento. Alguém lhe trouxe um pedaço de cuscuz com leite. Estacionou agulha e linha e comeu. Construiu uma figura triste. Do nada, irrompeu numa careta grotesca e chorou. É muito triste uma mulher comendo e chorando. Ainda mais viúva. Comeu até a última gota. Levantou-se e caminhou até Jesus. Beijou o quadro na altura do coração. A vela apagou-se, só se via a luz no coração de Cristo. Deus!! Jogaria terra sob o morto. Murmurando, pedia força para fazê-lo.

Um cortejo entornou na cama o corpo. Cabisbaixos, retiraram-se. O silêncio. Um silêncio que esfriava o sangue e que parecia nunca mais ir embora. 
VE1

Quer vesti-lo, fia?

VE2

Ou quer que nóis ajude?

VIÚVA

Não. Pode trocá.

\section{CONTADOR(A)}

Um minuto depois, deixou escapar...

VIÚVA

Nunca que vi Etevaldo nu.

\section{CONTADOR(A)}

Revelou. Como se nem ela mesma quisesse ouvir aquela confissão.

\section{VIÚVA}

Fechava os olhos quando ele me machucava.

\section{CONTADOR(A)}

À noite. No breu. Através do lençol. Desconhecia aquele corpo, mas amava-o. Confessou, roxa de vergonha. E era a primeira vez que ela falava com alguém mais que duas sentenças.

\section{VIÚVA}

Se for pra eu trocá, vou ter que apagar o candeeiro. Aí vai dar uma trabalheira da gota serena.

\section{CONTADOR(A)}

Pediu que ficassem. Virou de costas e instrumentalizou-as com o terno. Recolhida. Como se houvesse alguma indecência em ver o marido nu. As velhinhas vestideira começaram a descascá-lo com técnica e indisfarçável contentamento.

\section{VE2}

Quanta virtude, meu amor.

VE1

Mas quem viu já conhece...

VE2

...Quem nunca viu não sabe o que é.
VE 1 e 2

"Veste esta mortalha

Quem mandô foi Deus;

Quem mandô vestir

Foi a mãe de Deus.

Amarre este cordão

Quem mandô foi Deus;

Quem mandou marrá

Foi a mãe de Deus

Calça essa meia

Quem mandô foi Deus;

Quem mandô vestir

Foi a mãe de Deus

Calça esse sapato

Quem mandô foi Deus;

Quem mandô calçá

Foi a mãe de Deus

Bota no caixão (ou rede) Quem mandô foi Deus;

Quem mandô Botá...

VE1 (interrompendo o canto)

Oxente, cadê?.

\section{CONTADOR(A)}

A viúva já tinha entregue o paletó.

\section{VE1}

Maria de Deus, cadê a trouxa?

\section{CONTADOR(A)}

Assustou-se a velha.

VE!

Faz tempo que eu num vejo um, mas isso aqui não é peru.

VE2

Não se avexe não. Espie melhor. Procure direito.

CONTADOR(A)

De costas, a viúva se perguntava ... 
VIÚVA

Que trouxa?

VE2

Deve de tá escondido. Às vez tem que ajudar pro bichinho florescer.

VE1

Mulé, ou eu perdi a vista de vez ou a piroca dele é do tamanho de um cabelo de sapo.

VE2

Deixe eu lhe ajudar ...

VE1

Menina, cadê a bilola?

VE2

...a bilunga?

VE1

...a bimba?

VE2

....o ganso?

VE1

....a macaca?

VE2

....a peia?

VE1

...o maranhão?

VE1

...a manjuba?

VE2

....a macaxeira?

VE1

....a pomba?

VE2

....o pororó?

VE1

o quiri? Olhe ali.

VE2

Não, não tá.

VE1

Creio em Deus Pai todo Poderoso..

VE2

Olhe a teta.

VE1

Menino, isso parece uma quirica

VE2

Creio em Deus Pai, mulher. É um tabaco.

VE1

É mulher. É mulher.
CONTADOR(A)

Disse e saíram correndo casa afora.

AS VELHAS

O marido dela é fêmea!!

\section{VIÚVA}

Posso me virar?

\section{CONTADOR(A)}

Súbito, uma multidão fez fila na porta do quarto. Uma mulher despida sob a cama e outra de costas olhando o retrato de Jesus.

A viúva não entendia nada. Não entendia a morte. Não entendia homem. Naquele momento, só entendia a perda. Incrédulos, alguns faziam o sinal da cruz, outros se penduravam na janela para procurar atentos pelo peru. Já havia quem tomasse partido dela.

VOZ1

"Foi enganada a coitadinha. A sem-vergonha iludiu a bichinha."

CONTADOR(A)

Outros mais radicais:

VOZ2

"Elas vieram foi fugida para sujar nosso lugar com essa mundiça."

\section{CONTADOR(A)}

Facções se formavam e a notícia galopava.

Nisso, o padre chegou e foi direto cobrir o defunto, ou melhor, a defunta. Expulsou a todos. Trancou-se mais ela. Ressuscitou um candeeiro. Tomou coragem várias vezes para falar algo. Ponderado, começou:

PADRE

Minha filha, você dormiu com uma mulher.

\section{VIÚVA}

Não, seu padre, eu dormi com Etevaldo. E nunca que gostei. Sabia que num devia. 
PADRE

Creio em Deus Pai.

VIÚVA

É por isso que o senhor tá brabo?

PADRE

Não.

VIÚVA

Dormimo junto porque ele gostava. Mas ele me jurou casamento. Se o senhor quiser, eu me caso com ele morto mesmo. O vestido tá aqui guardado.

PADRE

Não é ele, mocinha. É ela.

VIÚVA

É Etevaldo! Benza ele, benza.

PADRE

Nunca!

VIÚVA

Benza, padre, ele é devoto de Santo Antônio. Temente a Deus. Queria até casar na Igreja.

PADRE

Vou rezar por você.

VIÚVA

Por mim, não, padre. Reze por ele. Ajude ele a morrer.

PADRE

Não posso. Morreu em pecado escuro.

VIÚVA

Dê descanso a sua alma.

PADRE

Tenho que chamar o bispo na capital.

VIÚVA

Abençoe o sono dele.

PADRE

Não posso! Todo mundo sabe que eu a vi sem roupa.

VIÚVA (chorando e corrigindo)

Etevaldo...

PADRE

Etevaldo. Eles sabem que eu sei que ele é mulé. Pelo menos se tivesse me chamado antes, nós teríamos feito de outro jeito. Ninguém tomaria conhecimento, minha filha. Já enterrei gente que nem você e ela... Etevaldo. Gente que morreu fazendo menos barulho.

(Pausa) Você o ama?
VIÚVA

Num sei o que é isso não. Eu queria ir mais ele. PADRE

Que Deus lhe abençoe. (Abre a porta aos gritos) Herege! Herege!!

\section{CONTADOR(A)}

Estatelada no chão, viu o padre sair da casa. Levantou-se a custo. A casa estava vazia agora. Escura. Agarrou-se ao candeeiro. Cobriu seu marido. Sem investigar-lhe a nudez. Incomodou-a estar só. Queria cantar para ouvir alguém. Não sabia se Jesus estava com ela ou não. Tinha Deus como uma certeza, mas às vezes achava que Deus podia aparecer, tomar um café, enrolar um fumo. Ficar mais íntimo. Gritos rodeavam a casa.

\section{VOZES}

"Belzebu!".

CONTADOR(A)

O delegado apeou na porta dela.

\section{VOZES}

"Filhas do Demo!"

CONTADOR (A)

Disparou uns três tiros pro alto para tanger o gado revolto.

VOZES

"Mulesta da peste!"

CONTADOR (A)

Mugiram contrafeitos, mas desmilinguiram-se para dentro das moitas. Entrou chutando a porta. Arrastava-se e trazia uma nuvem de muriço$\mathrm{ca} /$ mosquito em torno do seu cheiro. Sentou-se de frente para a viúva. Nem olhou o defunto.

\section{DELEGADO}

A senhora provocou uma desordem arretada nos arredores. Sabe quem eu sou? Num me conhece, não? Pois eu sou o delegado. Vim a mando do Coronel Heráclito, conhece? Conhece, sim. 
Trabalhou nas terra dele. Foi ele quem lhe deu sustento. bucho.

Disseram que a senhora nunca que pegou

Uns até desconfiavam, mas acharam que a gala de seu marido era rala. Coronel num gostou de saber de sua historinha, não.

Mandou vim ver de perto essa semvergonhice. A senhora deve de saber que amanhã findando o enterro, a senhora vai presa. Isso quer dizer depois que a senhora arranjar um lugar para enterrar seu macho.

(ri).

Ele mandou dizer que nas terra dele não se enterra. Vocês são que nem as quenga, as rapariga, as catráias, as sapuringa, que são tudo enterrada longe, no eito, nas brenha esquecida.

Nas terra dele só esterco bom. E vocês fedem a adubo estragado.

Vai ter que arranjar outro chão para enfiar esse corpo. Se enterro nesta terra, erva daninha nasce.

\section{(olhando o caixão)}

Menino, não é que ele é mulher mesmo? Mas é feio feito um macho. E tu ainda tratou bem dessa mulé. Tá gorda que nem filho de ladrão quando o pai tá solto. E tu num sabia que coronel num gosta dessa esfregação de fêmea com fêmea. Sua saboeira safada. Amanhã, na cadeia, a senhora vai conhecer macho para nunca mais se confundir.

E para gente num se confundir, para todo mundo saber qual é a tua raça, coronel quer lhe marcar a cara, como deve se ser feito com todas as vacas do rebanho. (Sai o delegado)

\section{CONTADOR(A)}

Ela se sentia um prato de comida estragada. Uma carniça. Um penico. Um escarro. Uma doença. Um pus. Um cancro. Uma gota. Suja, suja, imunda. E não entendia porque. Não tinha cabeça para entendimentos.

Se pudesse falaria no ouvido de Deus. Cantou sua fé com devoção sincera, o que dá no mesmo. Olhe, Música e Deus ninguém vê.
Fé ninguém toca, nem se mede. Mas juro: acontecia livre cada centímetro de Jesus, na voz dela. Tempo de seu canto. Cena parada. Contador a acompanha com instrumento.

\section{CONTADOR(A)}

Lembrou da dor e do alívio. A única imagem era a da mãe. Que fechava feridas com um sopro e ervas. Lembrou quando sangrou de chico da primeira vez. Ela gritava: "Mãe, tô vazando sangue". E a mãe dizia: "É assim mesmo, fia. Crescer dói, de vez em quando". Era a imagem de ninho que precisava para dar-lhe forças. E parecia ter o rosto da mãe desenhado na parede interna da pálpebra. Sua mãe cuidando da prole. Morrendo de fome, mas alimentando a cria. Sabia que ela cortaria uma mão se lhes faltasse carne pra comer. Amor? o que seria isso? Dor e alívio? Quando dava de chover, sua mãe punha os filhos tudo na chuva para aguar. Para crescer rápido. E só saíam de lá quando a chuva minguasse.

Queria estar com a mãe, queria ter ido no lugar dela quando morreu. Assim como trocaria de lugar com Etevaldo agora.

(Pausa)

Foi só delegado sair latindo pelo caatinga, e os gritos voltaram. Um grupo velou a madrugada inteira com impropérios, xingamentos, escárnios, maldiçōes, pragas. Criaram um ódio.

Desenterraram a pior parte deles.

Desenterraram as piores palavras da língua.

Nem bem a madrugada se punha, trancaram portas e janelas da casa delas. Envergonhavam-se delas. Queriam apagá-las de suas memórias. Cercaram a casa. Enterravam-nas vivas.

Não se sabe quem foi, quantos eram. Nem quem acendeu o primeiro fósforo. Começaram a incendiar o casebre.

Mal sabiam que, dentro, a viúva agradecia a benção de morrer com Etevaldo.

Temia muito mais viver sem ele, por certo. Tinha cantado bonito, Deus tinha lhe ouvido afinal. O fogo já empenava as paredes. 
Mesmo assim, a viúva acendeu o candeeiro. Viu-se por inteiro pela primeira vez. Descobriu então o que era mulher. Pôs-se ao lado de Etevaldo.

Beijou-o. Na boca. O que nunca tinha feito. Abriu-lhe os olhos no meio do beijo, enquanto o fogo ganhava a casa inteira.

(Pausa)

O dia amanhecia e as fagulhas resistiram queimando por dias. Cinzas. Silêncio. As fagulhas, em suspenso, como um eco, pairavam, sobre lavouras, varais e gerações.

FIM

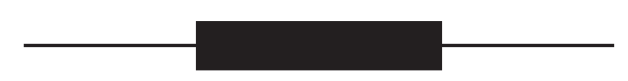

\section{Apêndice}

\section{CONTADOR}

"Uma lavadeira, um beija-fulô.

Lavava os paninhos

De Nosso Sinhô.

Quanto mais lavava

Mais sangue corria,

Nossa senhora chorava

E o judeu sorria...”

Cruel, a natureza é

Dá o sol na desmedida

Dá um corpo na desmedida

Dá o amor na desmedida. 